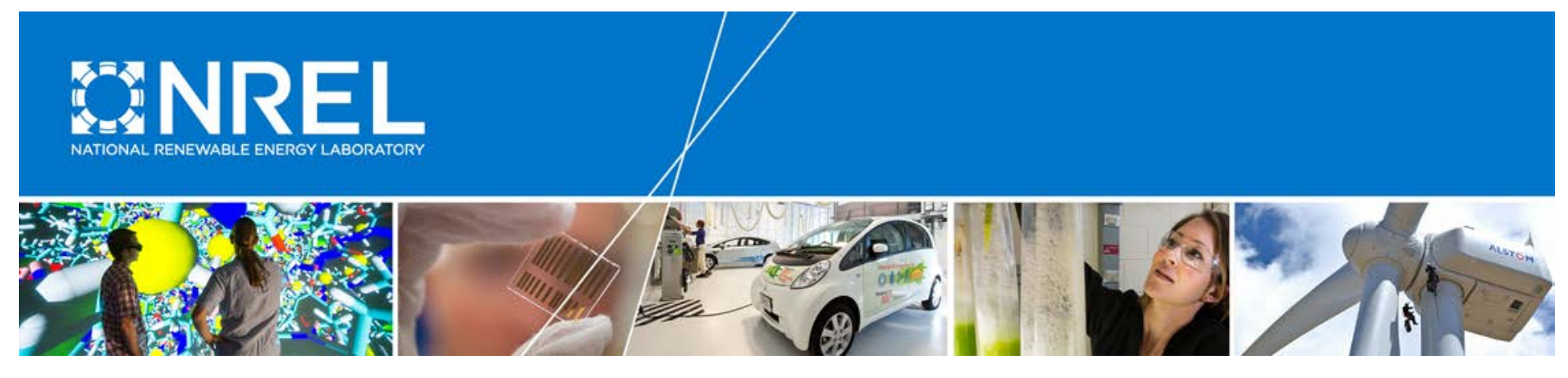

\title{
Cost-Optimal Pathways to $75 \%$ Fuel Reduction in Remote Alaskan Villages
}

\section{Preprint}

Travis Simpkins, Dylan Cutler, Brian Hirsch, Dan Olis, and Kate Anderson National Renewable Energy Laboratory

Presented at the 2015 IEEE Conference on Technologies for Sustainability - Engineering and the Environment (SusTech) Ogden, Utah July 30 - August 1, 2015

(C) 2015 IEEE. Personal use of this material is permitted. Permission from IEEE must be obtained for all other uses, in any current or future media, including reprinting/republishing this material for advertising or promotional purposes, creating new collective works, for resale or redistribution to servers or lists, or reuse of any copyrighted component of this work in other works.

NREL is a national laboratory of the U.S. Department of Energy Office of Energy Efficiency \& Renewable Energy Operated by the Alliance for Sustainable Energy, LLC

This report is available at no cost from the National Renewable Energy Laboratory (NREL) at www.nrel.gov/publications.

\section{Conference Paper}

NREL/CP-7A40-64491

October 2015 


\section{NOTICE}

The submitted manuscript has been offered by an employee of the Alliance for Sustainable Energy, LLC (Alliance), a contractor of the US Government under Contract No. DE-AC36-08GO28308. Accordingly, the US Government and Alliance retain a nonexclusive royalty-free license to publish or reproduce the published form of this contribution, or allow others to do so, for US Government purposes.

This report was prepared as an account of work sponsored by an agency of the United States government. Neither the United States government nor any agency thereof, nor any of their employees, makes any warranty, express or implied, or assumes any legal liability or responsibility for the accuracy, completeness, or usefulness of any information, apparatus, product, or process disclosed, or represents that its use would not infringe privately owned rights. Reference herein to any specific commercial product, process, or service by trade name, trademark, manufacturer, or otherwise does not necessarily constitute or imply its endorsement, recommendation, or favoring by the United States government or any agency thereof. The views and opinions of authors expressed herein do not necessarily state or reflect those of the United States government or any agency thereof.

This report is available at no cost from the National Renewable Energy Laboratory (NREL) at www.nrel.gov/publications.

Available electronically at SciTech Connect http:/www.osti.gov/scitech

Available for a processing fee to U.S. Department of Energy and its contractors, in paper, from:

U.S. Department of Energy

Office of Scientific and Technical Information

P.O. Box 62

Oak Ridge, TN 37831-0062

OSTI http://www.osti.gov

Phone: 865.576.8401

Fax: 865.576.5728

Email: reports@osti.gov

Available for sale to the public, in paper, from:

U.S. Department of Commerce

National Technical Information Service

5301 Shawnee Road

Alexandra, VA 22312

NTIS http://www.ntis.gov

Phone: 800.553 .6847 or 703.605 .6000

Fax: 703.605.6900

Email: orders@ntis.gov 


\title{
Cost-Optimal Pathways to $75 \%$ Fuel Reduction in Remote Alaskan Villages
}

\author{
Travis Simpkins, Dylan Cutler, Brian Hirsch, Dan Olis, Kate Anderson \\ National Renewable Energy Laboratory \\ Golden, $\mathrm{CO}$ \\ travis.simpkins@nrel.gov
}

\begin{abstract}
There are thousands of isolated, diesel-powered microgrids that deliver energy to remote communities around the world at very high energy costs. The Remote Communities Renewable Energy program aims to help these communities reduce their fuel consumption and lower their energy costs through the use of high penetration renewable energy. As part of this program, the REopt modeling platform for energy system integration and optimization was used to analyze cost-optimal pathways toward achieving a combined $75 \%$ reduction in diesel fuel and fuel oil consumption in a select Alaskan village. In addition to the existing diesel generator and fuel oil heating technologies, the model was able to select from among wind, battery storage, and dispatchable electric heaters to meet the electrical and thermal loads. The model results indicate that while $\mathbf{7 5 \%}$ fuel reduction appears to be technically feasible it may not be economically viable at this time. When the fuel reduction target was relaxed, the results indicate that by installing high-penetration renewable energy, the community could lower their energy costs by $21 \%$ while still reducing their fuel consumption by $54 \%$.
\end{abstract}

Keywords-REopt; microgrid; remote community; renewable energy; diesel renewable hybrid power systems

\section{INTRODUCTION}

Despite obvious differences in climate and ecology, the circumpolar Arctic has much in common with equatorial islands and other remote temperate locations, namely numerous isolated, diesel-powered microgrids that incur high energy costs and complicated fuel delivery logistics. There are over 4000 of these small $(<1 \mathrm{MW})$ diesel-powered microgrids scattered around the globe [1]. Yet a reported 1.3 billion people, living largely in rural areas, still lack access to electricity [2]. The International Energy Agency suggests that $70 \%$ of this population could be served most cost effectively by diesel-renewable-battery systems [3]. The design and operation of such small-scale hybrid systems presents significant technical challenges regardless of where they are located, though the challenges are often exacerbated in polar or tropical installations.

Sponsored by the U.S. Department of Interior, the Remote Community Renewable Energy (RCRE) program aims to reduce fossil fuel use and energy costs in remote, electrically isolated communities through high penetration, dieselrenewable hybrid systems. The multiphase program has a goal of developing an integrated system architecture and microgrid controller that is both modular and scalable, with the potential of reducing the cost of constructing small-scale hybrid microgrids in isolated communities. The resulting microgrid hardware would accommodate a high penetration of renewable energy and ultimately be demonstrated in an Artic community. Stakeholder engagement to encourage commercialization and deployment is also part of the RCRE effort.

To better understand and quantify the potential cost savings of such high renewable penetration microgrids, a technoeconomic model was developed for use in remote Alaska villages as part of the RCRE program. The model was used to analyze cost-optimal pathways toward achieving $75 \%$ fuel reduction in a remote Alaskan village. This paper describes the model and presents the results from the case study.

In this paper we present a framework and a methodology for analyzing cost optimal approaches toward achieving significant fuel reduction for both thermal and electrical loads in remote communities. The results from the case study are not intended to be conclusive, but rather are intended to illustrate the characteristics of the candidate set of technologies that was included in the analysis.

\section{APPROACH}

The REopt modeling platform for energy system integration and optimization [4] was used to evaluate different scenarios for reducing fuel consumption and energy costs in remote communities. REopt is a techno-economic model offering concurrent, multiple technology integration and optimization capabilities to help clients meet their cost savings and energy performance goals.

Formulated as a mixed integer linear program, the REopt model recommends an optimally sized mix of conventional and renewable energy, demand management, and energy storage technologies; estimates the lifecycle cost associated with implementing those technologies; and provides the costoptimal dispatch strategy for operating them at maximum economic efficiency. The REopt platform can be customized to address a variety of energy optimization scenarios including policy, microgrid, and renewable energy screening applications.

For this project, the REopt model was used to evaluate least-cost pathways toward achieving a $75 \%$ reduction in diesel fuel and fuel oil consumption through the use of a combination of alternative technologies, including wind, battery storage, and dispatchable electric heaters with thermal storage. 


\section{A. Data Collection and Load Analysis}

The coastal village of Unalakleet, Alaska, was selected as the basis for the case study in this analysis. An electrical load profile of the community was assembled from measured data that was provided by the local utility. The measured data was high resolution but included only about $40 \%$ of a year. The small gaps were filled using adjacent days while month-long gaps were filled using symmetric months (e.g. March data was replicated for October.) The production from the existing wind turbines was added to the measured data such that the resulting load profile represented the total electrical demand of the village. This reconstructed load would represent a community that had not yet begun installing renewable energy technologies.

The total energy use was 4.6 million $\mathrm{kWh}$ per year, with an average load of $522 \mathrm{~kW}$. The load ranged from a minimum of $306 \mathrm{~kW}$ to a maximum of $768 \mathrm{~kW}$ and therefore had a $68 \%$ load factor. The cost of diesel fuel for electricity generation was assumed to be $\$ 3.68$ per gallon (including available subsidies) escalating at $1.1 \%$ per year in nominal dollars. The escalation rate was calculated based on fuel price projections obtained from the Alaska Energy Gateway [5].

The annual thermal load for the village was estimated to be 40,000 MMBtu per year based on the total annual fuel oil consumption for heating. Since hourly data was unavailable, a thermal load profile was constructed using building energy models for a typical mix of buildings in the Alaskan climate zone. The building mix was estimated to be $80 \%$ housing, $16 \%$ school, and 4\% retail stores. The BEopt [6] residential energy modeling software was used to simulate the load of the single family homes while the school and retail store loads were simulated using EnergyPlus [7] based on the Commercial Reference Buildings models [8]. Fuel oil was assumed to cost $\$ 6.45$ per gallon (no subsidies were available for fuel oil), again escalating at $1.1 \%$ per year.

Both the electrical load and the thermal load were assumed to remain constant over the analysis period. Energy efficiency measures for the building stock were not considered as part of this analysis.

\section{B. Model Description}

The REopt model is a mixed integer linear program that performs an energy balance at every time step. The objective function is to minimize the lifecycle cost of energy over the analysis period, where lifecycle cost includes the capital cost of the equipment, operating and maintenance (O\&M) costs, and fuel costs.

This analysis used 8760 time steps such that the seasonal variation in the load and resource availability over the course of a year was captured by the model. The resulting optimized energy balance for one year was then assumed to exist for all subsequent years in the 25 year analysis period. The fuel escalation rates as well as a discount rate of $2.5 \%$ were used to translate costs in future years to the present. The key constraints of the model included:

1. The electrical load must be met in each time step by a combination of the existing diesel generator, wind, and battery.
2. The thermal load must be met in each time step by a combination of the existing fuel oil heating and the dispatchable electric heaters with thermal storage.

3. Fuel consumption (electrical and thermal) must be less than or equal to $25 \%$ of the current use (fuel reduction case only).

The following candidate technologies were included in the model for consideration and are further described below: diesel generators, fuel oil heating, wind, battery storage, and dispatchable electric heaters with thermal storage. These technologies were selected for consideration based on expert guidance and recommendations, though other technologies such as biomass or solar photovoltaics may also play a role now or in the future.

\section{1) Diesel generators}

The performance of the diesel generator was modeled using a linear fuel burn rate with slope of 0.06 gallons per $\mathrm{kWh}$ and $y$-intercept of 2.8 gallons per hour, based on fuel data for a 328 $\mathrm{kW}$ generator. The minimum turn down ratio was assumed to be $30 \%$ and there was assumed to be no waste heat recovery system.

There was no capital cost associated with the generators as they were assumed to already exist in the community and would therefore not constitute a new expense. The O\&M cost was assumed to be $\$ 0.02$ per $\mathrm{kWh}$ produced, and it was expected that the system would last 25 years.

A lumped model of the diesel generator was used, meaning that all of the generating capacity specified by the model was assumed to be in one large generator rather than multiple smaller generators. Spinning reserve and operating reserve were not considered as part of this analysis.

The diesel generator could directly serve the electrical load or charge the battery.

\section{2) Fuel oil heating}

The village currently uses fuel oil to supply their thermal loads. Although the fuel oil heating is distributed around the village, they were modeled as a single lumped heater module capable of converting fuel oil to heat with an efficiency of $80 \%$. There was no capital cost associated with the fuel oil heating technology since it was assumed to already exist.

The fuel oil heating technology could directly serve the thermal load.

\section{3) Wind}

Wind was modeled as large utility-scale wind turbines at a total installed cost of $\$ 6000$ per $\mathrm{kW}$ and an O\&M cost of $\$ 35$ per kW per year [9]. The units were expected to last 25 years.

The wind resource data was obtained from the Modern Era Retrospective Analysis for Research [10] dataset for the Unalakleet site and represents a long term annual average for the site. The resource indicates that wind turbines in this location could be expected to operate at an average capacity factor of $38 \%$, with a very large dynamic range of $0 \%$ to $85 \%$ and a large standard deviation of $33 \%$. 
Electricity produced by the wind turbines in the model could be used to serve the electrical load, charge the battery, or power the dispatchable electric heaters, thus indirectly serving the thermal load.

\section{4) Battery storage}

The battery storage module was based on the characteristics of lithium-ion batteries. The model was able to optimally select and size both the capacity of the battery and the power delivery. Battery capacity was assumed to cost $\$ 620$ per $\mathrm{kWh}$ and power delivery $\$ 350$ per $\mathrm{kW}$ [11]. The life expectancy of the battery was assumed to be 10 years, and the amortized replacement cost was included in the model. The battery was modeled with a combined round-trip efficiency of $70 \%$ and discharge was restricted to ensure that the state of charge (SOC) never dropped below 20\%. The battery can be charged by the generator or the wind turbines and discharged to the electric load.

\section{5) Dispatchable electrical heaters with thermal storage}

Dispatchable electric heaters are a specialized technology deployed in remote Alaskan villages. Located in residential housing, businesses, or schools, these heaters are connected to the utility via mesh network such that they can be switched on by a microgrid controller during periods of excess wind. Each unit contains integrated thermal storage, typically in the form of ceramic bricks which allows extra heat produced during windy periods to be used later when the wind is calm.

The dispatchable electric heater module was developed based on units that are deployed in the field [12]. Each unit in the model could be commanded to produce up to $6 \mathrm{~kW}$ of heat and could store $34 \mathrm{kWh}$ of heat for later use. The cost of each unit was assumed to be $\$ 3000$ [13].

The thermal energy stored in one of these units was assumed to decay at a rate of $15 \%$ per hour, meaning that some thermal energy was discharged even when the unit was commanded to be off. Since the units are located indoors, however, this thermal energy was assumed to not be lost to the environment, but rather could continue to serve the thermal load, albeit at perhaps a time other than that which was specified.

The model was constrained to limit the number of heaters to 500 which represents approximately two per house in addition to deployment in the schools and retail establishments.

\section{Scenarios}

The model was used to evaluate three scenarios, each of which would meet the energy requirements of the community at minimum lifecycle cost over the 25 year analysis period.

1) Base case: The candidate pool of technologies in the base case was restricted to include only the diesel generator and fuel oil heating. This was used to establish a baseline lifecycle cost of supplying energy to the community if the community were to continue doing "business as usual" instead of implementing alternative technologies.
2) Fuel reduction case: In the fuel reduction case, the candidate technologies were expanded to include wind, battery storage, and dispatchable electric heaters. The additional scenario constraint requiring the combined diesel fuel and fuel oil consumption to be reduced by $75 \%$ as compared to the base case was activated. The results for this case represent the least cost path to achieving $75 \%$ fuel reduction given the candidate technologies.

3) Economic case: In the purely economic case, the model was allowed to select from any of the candidate technologies but was not required to meet a fuel reduction target. The technologies selected by the model in this case result in the lowest lifecycle cost of energy for the community. It should be noted that the solution set of technologies for this case may also reduce fuel consumption, but that is merely a byproduct of the cost savings rather than an explicit requirement.

\section{RESULTS}

In the base case, the electrical load is met entirely by existing diesel generation which consumes 294,651 gallons of diesel fuel while the thermal load is met entirely by existing fuel oil heating which consumes 288,010 gallons of fuel oil. Therefore the baseline fuel consumption for the community is 582,661 gallons of fuel per year. The 25-year lifecycle cost for this base case scenario is $\$ 63.2$ million.

The fuel reduction case was run next to identify the technologies that would achieve a $75 \%$ fuel reduction at lowest lifecycle cost. The total fuel consumption permitted in this case was 145,665 gallons per year.

In the fuel reduction case, the load is met by a combination of $379 \mathrm{~kW}$ of diesel generators, 5.9 MW of wind, a $13 \mathrm{MWh}$ battery, and 500 dispatchable electric heaters. By adding wind, batteries, and dispatchable electric heaters, the total fuel consumed is reduced by $75 \%$ from the base case, as required by the scenario constraint. While the annual fuel costs are less in the fuel reduction case, there is a significant upfront capital investment required to purchase the wind turbines, batteries, and dispatchable heaters.

The lifecycle cost for the fuel reduction case is $\$ 69.1$ million. This is $9 \%$ more than the base case lifecycle cost indicating that the community would have to pay more for energy in order to achieve the $75 \%$ reduction goal. For this reason, this fuel reduction case could be considered to be not cost effective, though given the uncertainty surrounding the load data, wind resource, fuel costs, and other assumptions, this may be within the statistical noise of the model. Fig. 1 illustrates the sources of energy serving the electrical and thermal loads in the base case, fuel reduction case, and economic case, respectively. Fig. 2 depicts the fraction of time each energy system operates over the course of a year. Note that the system achieves diesel-off operation during a majority of the year. 


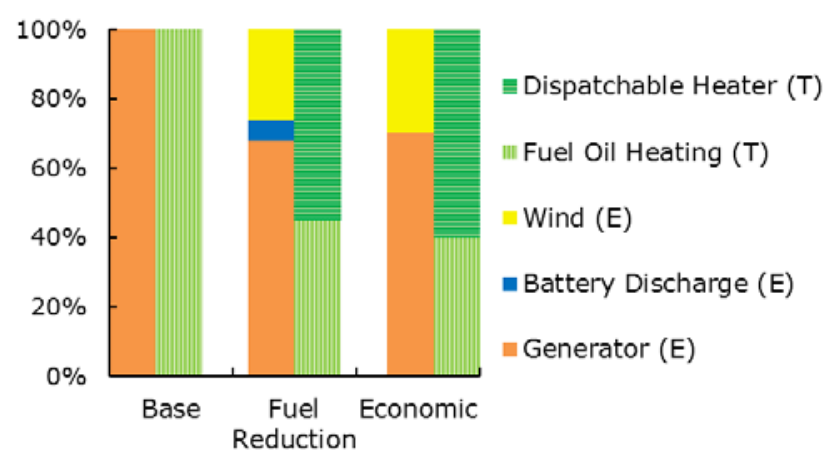

Figure 1. Sources of energy serving the electrical (E) and thermal (T) loads, respectively, in each scenario

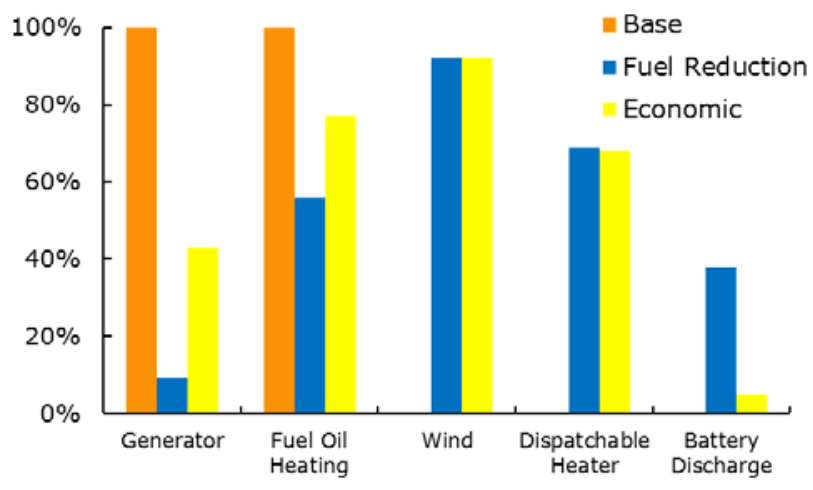

Figure 2. Fraction of the year that each technology operates in each scenario

To achieve a $75 \%$ reduction in fuel, the wind turbines must be significantly oversized compared to the electrical load. As shown in Fig. 3, only 16\% of the energy generated by the wind turbines serves the electrical load. The primary reason for this is that the only means of offsetting fuel oil consumption in the model is to build dispatchable electric heaters. Since each of these has only a limited quantity of storage, the wind turbines must be sized well beyond the size of the electrical load to insure sufficient excess wind is available to power the heaters. Fig. 3 shows that $41 \%$ of the wind energy powers the heaters, $15 \%$ serves the electrical load and $9 \%$ is used to charge the batteries. The remaining 35\% is curtailed, meaning that it has no economic value to the community as represented in the model.

Fig. 4 shows how the electrical load is met for a representative week in January. The highly intermittent nature of the Unalakleet wind resource is evident during this time period as the wind turbines are often meeting and actually exceeding the electrical load (excess wind is not shown in the figure) or not producing at all. During periods when the wind is not producing, the electrical load is met by a combination of the diesel generator and the battery.

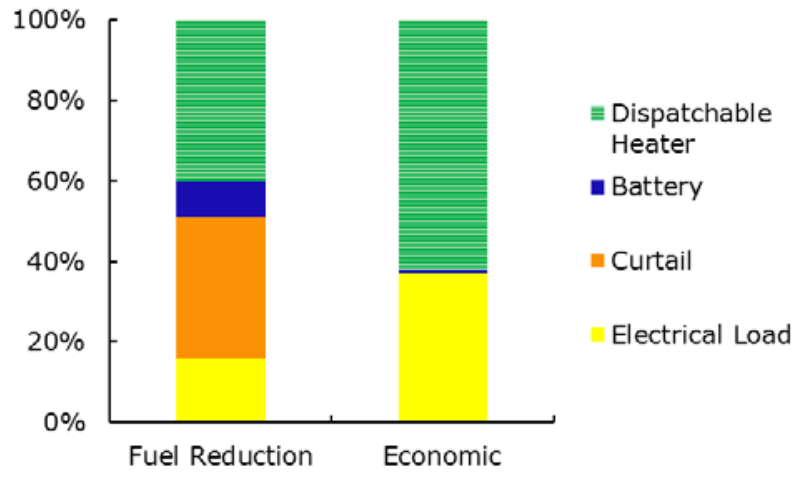

Figure 3. Distribution of wind energy by load served for the fuel reduction and economic scenarios

These model results indicate that a combination of diesel generation, fuel oil heating, wind, battery storage, and dispatchable electric heater can technically achieve the $75 \%$ fuel reduction target, albeit at a higher cost of energy to the community than they would otherwise incur. The large battery is required to store energy produced during periods of high wind production such that the system can still achieve dieseloff operation while the wind is calm. Since the objective of the RCRE program is to reduce energy costs along with fuel consumption, a third scenario was considered in which the $75 \%$ fuel reduction constraint was removed. This allowed the model to minimize the lifecycle cost of energy without regard for the amount of fuel consumed. This case is referred to as the economic case since the model is making decisions purely based upon economic performance.

In the economic case, the amount of wind in the solution set is reduced by half ( $2.5 \mathrm{MW})$ and the battery all but disappears as compared to the fuel reduction case. The lifecycle cost ( $\$ 49.5$ million) is reduced by $21 \%$ as compared to the base case, meaning that it would be economically feasible for the community to install these technologies since they lower the lifecycle cost of energy to the community. This solution also achieves a 54\% reduction in fuel, even without an explicit requirement to do so.

Table 1 compares the technology sizes, fuel consumption, and lifecycle cost for each of the three scenarios.

\section{DISCUSSION}

Although the model indicates that it is technically feasible to achieve a $75 \%$ reduction in fuel by installing a combination of wind, battery storage, and dispatchable heaters, it is marginally not economically viable to do so because it has higher lifecycle cost than the base case. In contrast, when the fuel reduction requirement is relaxed, the purely economic scenario indicates that significant fuel savings can occur while also saving money.

The results from the fuel reduction case show that the model has reduced the amount of diesel fuel to the generators by $94 \%$ while the amount of fuel oil is only reduced by $55 \%$. The hybrid system is required to achieve diesel-off operation for the vast majority of the year in order to meet the overall 


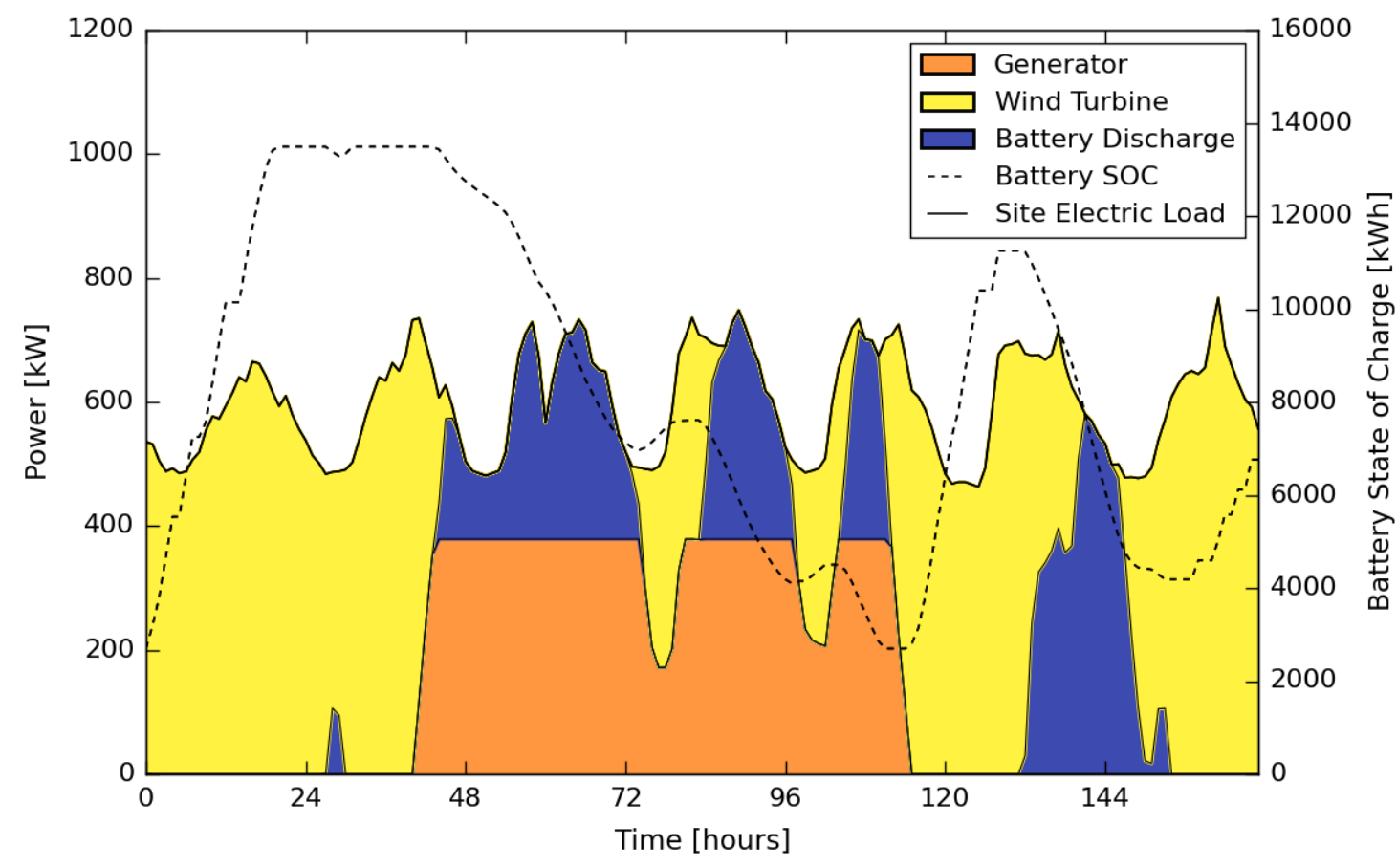

Figure 4. Cost-optimal dispatch strategy to meet the electrical load for a representative week in January

TABLE 1. TECHNOLOGY SIZES, FUEL CONSUMPTION, AND LIFECYCLE COST FOR THE THREE SCENARIOS

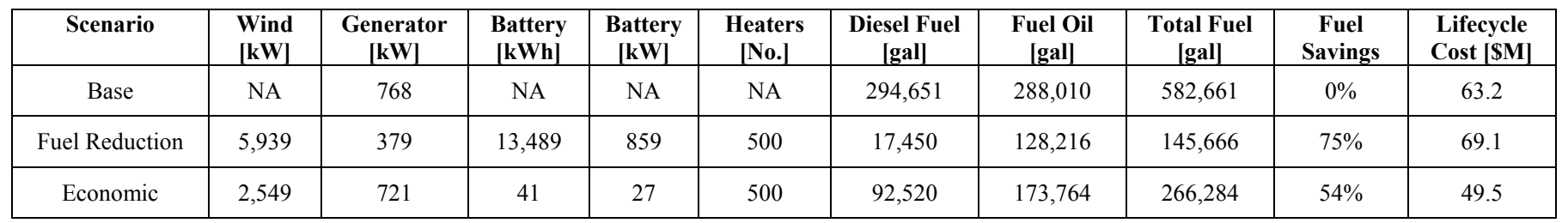

$75 \%$ fuel reduction target. This indicates that it is more costeffective to displace diesel fuel than fuel oil in the model.

It is important to recognize that the model does not consider voltage and frequency control and therefore it assumes system balancing requirements can be met when the diesel generator is offline. The system controller costs needed to achieve this are intended to be embedded in the battery system costs. However, diesel-off operation is non-trivial at this scale and presents a technical challenge which is being addressed in other areas of research within the RCRE program.

\section{FUTURE WORK}

The objective of the techno-economic modeling component of the RCRE program is to provide insights into the optimal mix and sizing of the technologies that may ultimately be included in a high-penetration renewable hybrid microgrid. This phase of the modeling demonstrated that hybrid renewable energy systems may be able to both significantly reduce fuel consumption and save money in isolated communities. Although this case study was based on the village of Unalakleet, it did not consider the wind turbines already installed there or the detailed characteristics of the existing conventional systems (such as heat recovery loops).
By including more detail on these systems, future modeling efforts could produce more refined results regarding a specific community such as Unalakleet.

Model enhancements are also planned to incorporate water treatment and conveyance into the model. Water treatment, including the heating of potable and wastewater, consumes a significant amount of energy in isolated Alaskan communities. By incorporating water tanks, these water treatment loads need not be temporally aligned with generation, and are thus well suited to hybrid renewable energy systems.

Other research within the RCRE program is focused on developing the control strategies needed to operate such highpenetration renewable hybrid microgrids, as well as modular, scalable, cyber-secure control and communication architectures that are designed to allow any microgrid component, such as a wind turbine, solar panel, diesel generator, or energy storage device, to intelligently connect and optimally contribute to the overall system energy demand. 


\section{CONCLUSIONS}

The REopt modeling platform for energy system integration and optimization used in this analysis provides a framework and methodology for evaluating different scenarios toward achieving 75\% fuel reduction in remote Alaskan villages. The scenarios presented are intended to provide insight regarding what might be possible rather than to serve as a design template for an actual system.

This analysis shows that hybrid systems may be economically viable in remote Alaskan communities, and can reduce fuel consumption in excess of $50 \%$ while simultaneously saving money. Achieving $75 \%$ fuel savings is more challenging, and is likely not economically viable at this time, though declining system costs could change this in the future. The model indicates that offsetting fuel oil may be the major challenge. Achieving greater than a 50\% fuel reduction, however, appears to be both technically and economically viable at the present.

\section{ACKNOWLEDGMENTS}

The RCRE program is funded by the Department of Interior and is a partnership between the National Renewable Energy Laboratory, the University of Alaska Fairbanks (Alaska Center for Energy and Power) and the Colorado State University (Engines and Energy Conversion Laboratory). The authors would like to thank The University of Alaska Fairbanks and Unalakleet Valley Electric Cooperative for providing data and expertise regarding the village of Unalakleet. The authors would also like to acknowledge Julieta Giraldez, Owen Roberts, and Scott Haase of the National Renewable Energy Laboratory for their contributions to the analysis.

\section{REFERENCES}

[1] C. Werner and Ch. Breyer, "Analysis of mini-grid installations: an overview on system configurations," in Proc. 27 th European Photovoltaic Solar Energy Conf., Frankfurt, Germany, 2012.

[2] International Energy Agency, "World energy outlook 2013," OECD/IEA, Paris, France, 2013.

[3] International Energy Agency, "Energy poverty: how to make modern energy access universal," OECD/IEA, Paris, France, 2010.

[4] T. Simpkins et al., "REopt: a platform for energy system integration and optimization," in Proc. $8^{\text {th }}$ International Conf. on Energy and Sustainability, Boston, MA, 2014.

[5] Community Data Summary: Unalakleet, Alaska Energy Data Gateway, [online] 2015, https://akenergygateway.alaska.edu/ (Accessed: 31 May 2015).

[6] P. Cesar Tabares-Velasco, J. Maguire, S. Horowitz, and C. Christensen, "Using the BEopt automated residential simulation test suite to enable comparative analysis between energy simulation engines," NREL Report No. CP-5500-62273, National Renewable Energy Laboratory, Golden, CO, 2014.

[7] N. Fumo, P. Mago, and R. Luck, "Methodology to estimate building energy consumption using EnergyPlus benchmark models," in Energy and Buildings, vol.42, is. 12, pp. 2331-2337, December 2010.

[8] M. Deru et al., "U.S. Department of Energy commercial reference building models of the national building stock," NREL Report No. TP5500-46861, National Renewable Energ Laboratory, Golden, CO, 2011

[9] Personal correspondence, National Wind Technology Center

[10] M. Rienecker et al., "MERRA: NASA's modern-era retrospective analysis for research and applications," in J. Climate, Vol. 24, pp. 36243648, 2011.

[11] Rocky Mountain Institute, "Economics of Grid Deflection," Februrary 2014, http://www.rmi.org/electricity_grid_defection (Accessed: 5 June 2015).

[12] D. Meiners, "Chaninik wind group multi-village wind heat smart grids final report," U.S. Department of Energy, 2013.

[13] Personal correspondence, technology vendors 